\title{
Case Study on Augmentation of Women's Jacket for the Indian Market
}

\author{
Priyalatha S*, Sanjula A, Sneha Jennifer P, Susmitha R and Swetha $\mathbf{R}$ \\ Department of Fashion Technology, Sona College of Technology, India \\ *Corresponding author: Priyalatha S, Assistant Professor, Department of Fashion Technology, Sona College of Technology, Salem, Tamilnadu, India \\ submission: 海June 27, 2018; Published: 海 September 24, 2018
}

\begin{abstract}
The jacket is less popular among Indian women and the main intention of this case study is to make the jackets popular by designing a suitable and comfortable jacket to be worn in all kinds of occasions. The data were collected in the pre-designing and post production stage in the form of feedback from women of the particular age group settled in the metropolitan cities. Based on the feedback obtained, market survey and forecast, the jackets were designed and manufactured for different end uses. Indian women eagerly want to have a new look with traditional touch without any criticisms. It can be fulfilled by the jackets which are no way lower in style and look. Multipurpose and easily wearable jackets are designed for the purpose of all kinds of customers like adventurous, classy, trendy and traditional wearers. The designed garments are very well recognized by the target people. The target customer circle can be widened. The number of designs in a collection can be increased so as to have wider options for their selection. This study provides data to understand the Indian women's state of mind and helpful in launching innovative woman jacket and taking Indian women a step ahead in the dressing sense with no possibilities for criticism and safety issues. This study tries to introduce jacket as a well accepted outfit with different styles by understanding customers' need.
\end{abstract}

Keywords: Women's jacket; Design development; Technical pack; Product development; Multipurpose jacket; Jacket styles; Customer feedback

\section{Introduction}

The jackets are said to have originated during the middle ages or Early Renaissance as the jerkin. By the early eighteenth century, the jacket became a standard working dress for those employed in Agriculture and Servants in urban settings. Single-breasted fitted jackets with darts under the arms, small lapel and waist pockets was popular in 1830's, and double-breasted styles in 1862 . The single-breasted Norfolk jacket, which had high raised neck was in trend. At the end of the nineteenth century, the three buttoned styles were believed to be fashionable. Jackets with silk-fronted lapels were worn to dinner parties. Sports jackets are still worn with flannels. In early 2000s jackets were not only associated with formal styles, it also includes sports jackets, blazers, bomber jackets etc. Originally cut in wool, tweed, cotton, leather.

From the below concepts, one could come to a conclusion that the consumers age, gender, lifestyle, occupation, economic condition is some of the factors that influences the fashion involvement. Based on these factors the target customers can be identified and the designs can be fashioned accordingly. Here our emphasis on the women belonging to Generation Y (1977-1995) and Gen Z (1996 and later).

"Dress like a boss without spending like one", this saying is appropriate for the ones fancying casual jackets. These casual jackets come at an affordable price and aims at putting the wearer at maximum ease. Casual jackets are suitable for several occasions and can also be used as everyday wear. By competing through development capability and the concept of a development strategy a new product can be developed. They mainly focused on the engineering process that lies behind new products, the integration of marketing, manufacturing, the role of senior management in guiding and leading the effort [1].

The fundamental relationships underlying the incorporation of a user orientation into the NPD process are examined. It is based on terms of enhancing collaborative new product development, improving idea generation, producing superior products or service solutions and facilitating product appropriateness and adoption [2].

The four types of involvement are consumption involvement, advertising involvement, purchase decision involvement and product involvement [3]. The main issues in fashion marketing are studied by directing distribution of a series of high-volume outlets in urban centers typically close to where people live and work businesses can make dramatic savings in fulfillment costs [4].

The consumption of luxury products by the generation Y groups are studied on the following perspectives: the influence of brand consciousness on consumption behaviors in terms on consumption motivations, the influence of self related personality traits on their brand consciousness, purchase intention, and brand loyalty [5].

Integrated human actions and complex socioeconomic themes, into the process of new product development to adapt its design to 
various competitive market. The main phases are as follows, theme generation, product design and detail engineering, product and process development and evaluation, product and market initiation [6]. The self-esteem, age, income, marital status and education of Indian women are focused on predicting their fashion clothing involvement. It is helpful to International and National apparel manufacturers and brands in planning, branding and marketing strategies to promote fashion clothing among Indian women [7].

The fashion clothing knowledge influences consumer confidence in making purchase decisions about fashion. This approach enhances the both theoretical and practical level understanding the consumer behavior related to fashion [8].

The practical understanding of consumer characteristics and their motivation to make purchase decisions for passing fashion can help retailers in developing marketing strategies to perform more effectively in the market [9]. The gender and acquisitiveness are significant drivers of fashion clothing involvement. Ongoing information search, recreational consumer identity, purchase decision involvement and market mavens are significant outcomes of fashion clothing involvement [10]. The authentic self-image of woman innovators and how their self-image differs from the buyers is focused [11].

The fashion clothing involvement is affected by a consumer's gender, age, degree alleged person-product image similarity and degree of acquisitiveness. It also publicized significant results through modeling product involvement in an outline of related constructs [12].

\section{Pre-design analysis}

Pre-design is the phase of analysis that is carried out before the actual designing begins. During this pre-design phase, studies are done to analyze the style, current trend and consumer desires to accomplish the market in the humanity.

\section{Market analysis}

The analysis is made to monitor the market trend and to understand the precise designs, styles, and colors used in women's jackets \& suits. Some unique features available in the market are Reversible jackets, embroidered leather jackets, fur jackets, buckle strap jackets etc. Only some of the popular brands suggest women's jacket because they are not much popular among Indian customers. Brands offer different kind of styles like double breasted blazers, Denim jackets, etc. to commensurate future trend in the market. Those jackets are predominantly preferred by high class consumers, high fashioned people, celebrities and high class business women. Thus, the designs for five different jackets as casual wear, occasional wear and biker jacket has been developed for the season of autumn - winter $2 \mathrm{k} 18$.

\section{Forecasting}

Forecasting is done for A/W season 2k18. Women's jacket for $\mathrm{A} / \mathrm{W}$ season requires a thick fabric capable of maintaining the normal body temperature. The forecasted fabrics are Wool, Tweed fabric, Cotton blend, Satin, Synthetic fabric (Nylon, polyester, Blended fabric, Velvet, Corduroy, Leather, Lace blazer, Denim fabric). Thus, the most preferred fabric for women's jacket is Lycra fabrics with good elasticity. The colors forecasted for A/W2k18 are dark shades such as Blue, Brown, Black, Olive Green, Navy blue, Red pear, Beige, Grey, Grey Melange. The Price ranges of the jackets available in the market are from RS: 1999 -Rs: 8999 and above.

\section{Designing}

Based on the market study and forecasting done 5 women's jackets were designed. The important factors to be considered while designing a garment is the comfort of the wearer, various features, silhouette, suitability for the target customers, price range, embellishments if required etc. From the forecasting done, the color, style, fabric, trims were chosen based on availability and suitability for season A/W2K18. Initially, designs were developed through rough sketches. Roughly sketched designs include some of the information such as the details of the component like the type of sleeve, collar, vent placement etc. the sketches containing this information is further sent for the approval. After getting the approval for the rough sketches, tech pack has been developed for jackets using adobe illustrator. Technical pack (Tech pack) is created to communicate with a manufacturer containing all the necessary components that are needed to construct a product. Suitable trims were chosen and are specified on the Technical pack. These Technical packs were sent for approval.

Based on tech pack, patterns are drawn with the exact measurements individually. Then by using marker planning the jacket patterns has been laid. After cutting and labelling, each component is sewed individually along with the trims like buttons and zippers using exact measurements. Jackets are the given in Figure 1 to 5 .

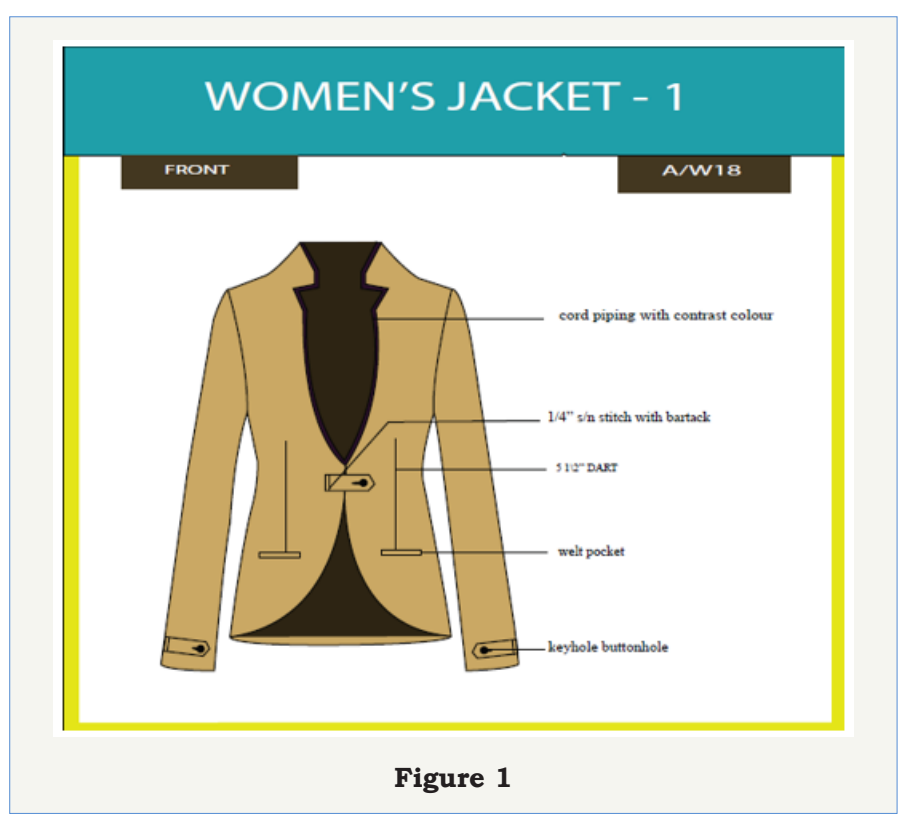




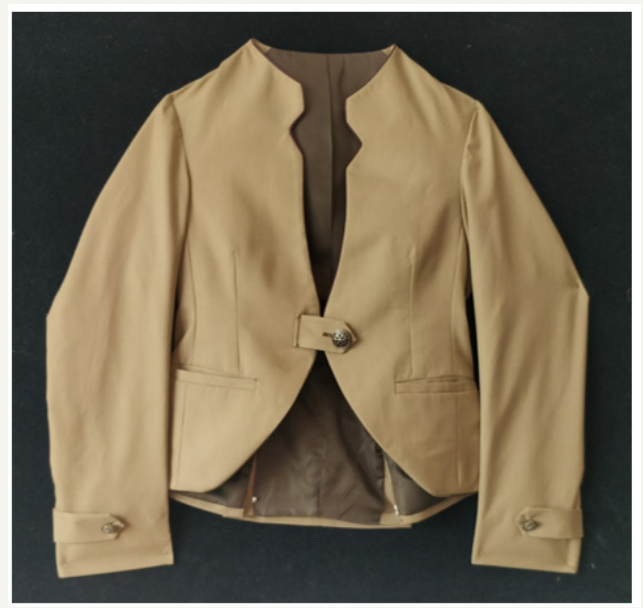

Figure 2: Jacket front.
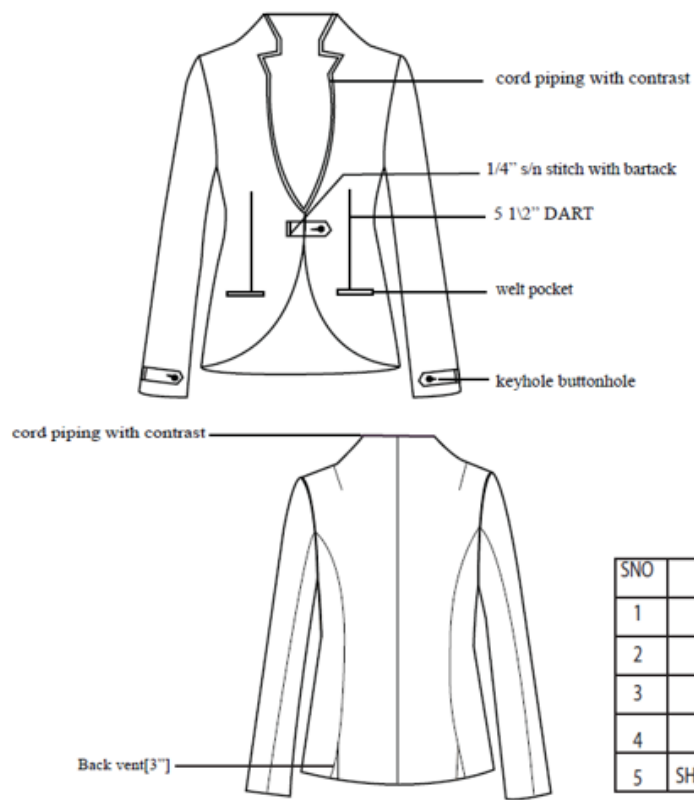

Figure 4: Technical pack of Design-1.

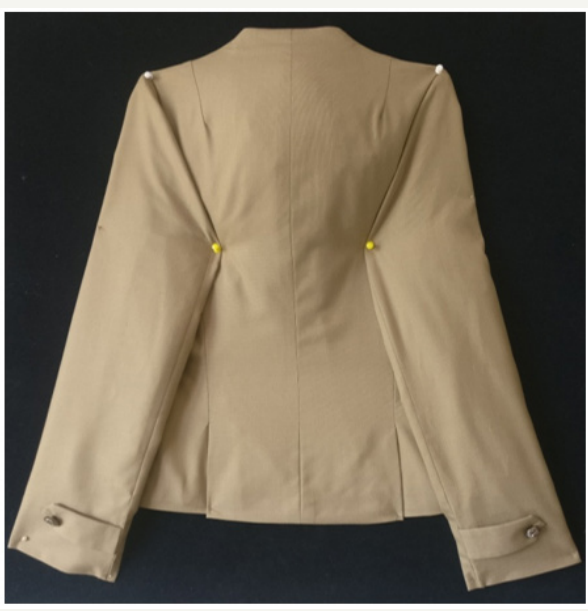

Figure 3: Jacket back.

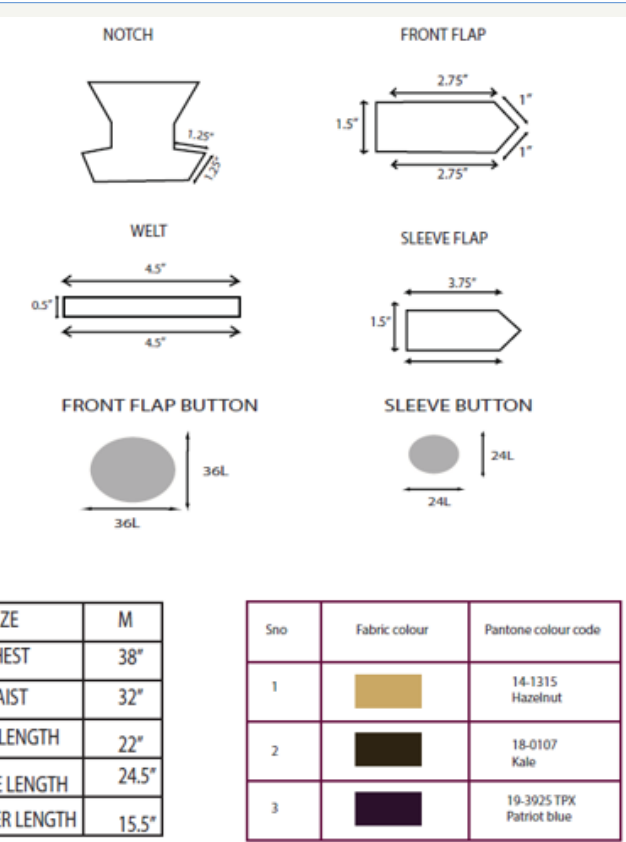

\begin{tabular}{|c|c|c|c|c|c|}
\hline SNO & SIZE & M & Sno & Fabick colour & Pantone colour codte \\
\hline 1 & CHEST & $38^{\prime \prime}$ & & & \\
\hline 2 & WAIST & $32^{\prime \prime}$ & 1 & & $\begin{array}{l}\text { lal1315 } \\
\text { Hazelout }\end{array}$ \\
\hline 3 & FULLLENGTH & $22^{*}$ & 2 & & 18.0107 \\
\hline 4 & SLEEVELENGTH & $24.5^{n}$ & & & \\
\hline 5 & SHOLUDER LENGTH & $15.5^{\circ}$ & 3 & & 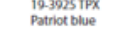 \\
\hline
\end{tabular}

\section{Designed women jackets}

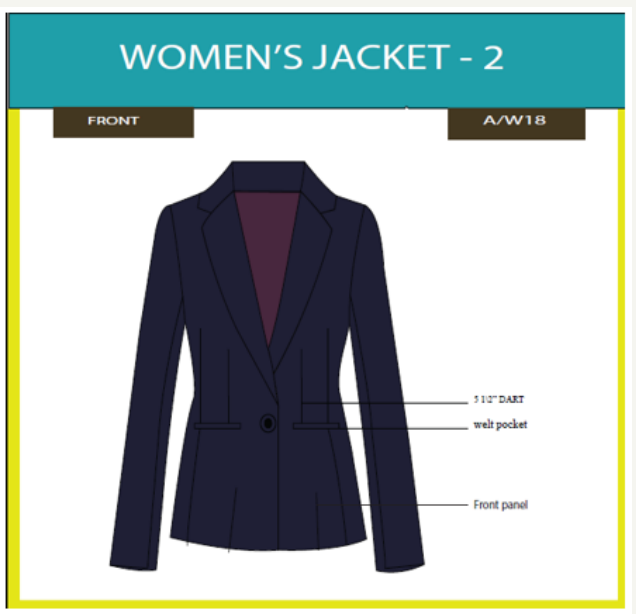

Figure 5

\section{Design description:(Figure 1-3)}

Design 1: This work wear jacket consists of wide open front upto waist with corded piping of contrast color. The triangular notches in the collar give a different look to the wearer. The straight cut welt pockets in the front and pointed flaps at the center front as closure is an interesting style feature in this garment and it is created based on the customer request to simplify the fastening process. The sleeve hem is also decorated with the similar pointed flap to add rhythm to the garment. A decorative metal shank button adds further interest and attracts the trendy working women in the metropolitan cities.This upper garment can be accompanied with formal pants, jeans, palazzo, formal skirts and scarfs/stole. To make the work going women dress up quicker in the early morning rushes, the fastening is made easier with single button provision (Figure 4-7). 


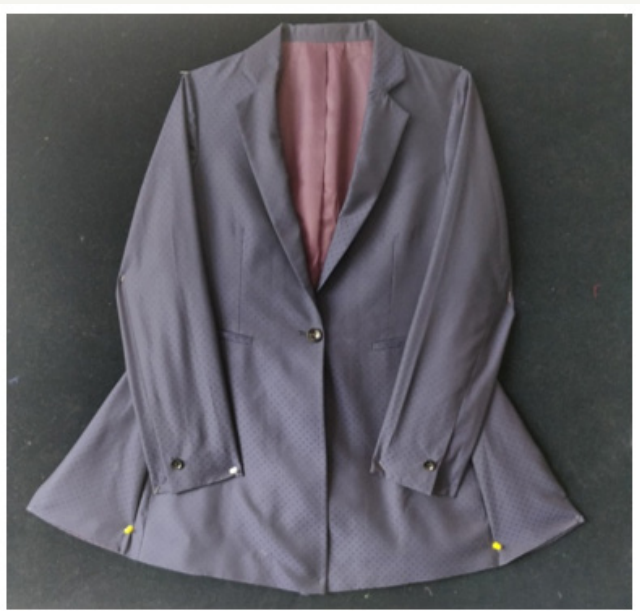

Figure 6: Jacket front.

Design 2: This flared jacket is made lengthier than the other styles to make the flares visible. It is a full sleeved jacket with buttons for decorative purposes and a single button for closure in the front.This jacket can be used as formal wear suitable for current trend. Choosing appropriate material gives this jacket a perfect flared look. The navy blue color chosen gives a professional look to the wearer. This jacket is designed mainly for slim women to give a

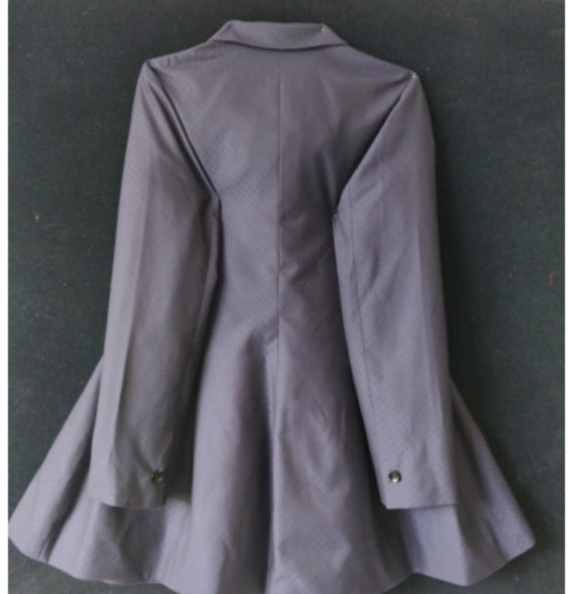

Figure 7: Jacket back.

little bulkier effect.It gives a decent covered look to the wearer. This flared jacket is designed in such a way that it cannot be criticized and gives a secured feeling to the wearer. This can be paired with pencil fit short skirts, jeans, jeggings and tank tops, tight fit t-shirts can be worn under this jacket. Brooches can be placed on the lapel for the decorative purpose (Figure 8-11).
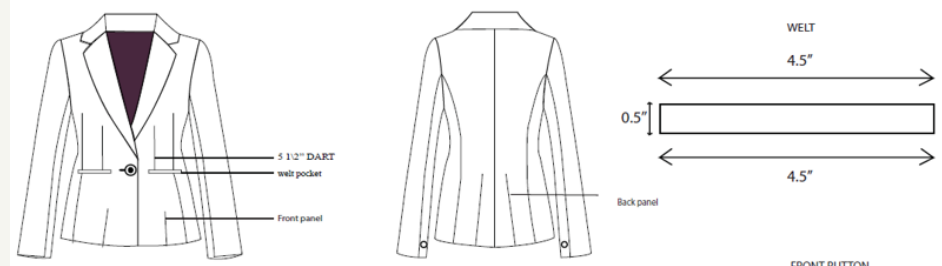

\begin{tabular}{|c|c|c|}
\hline SNO & SIZE & M \\
\hline 1 & CHEST & $38^{\prime \prime}$ \\
\hline 2 & WAIST & $32^{\prime \prime}$ \\
\hline 3 & FULL LENGTH & $22.5^{\prime \prime}$ \\
\hline 4 & SLEEVE LENGTH & $24.5^{\prime \prime}$ \\
\hline 5 & SHOLUDER LENGTH & $15.5^{\prime \prime}$ \\
\hline
\end{tabular}
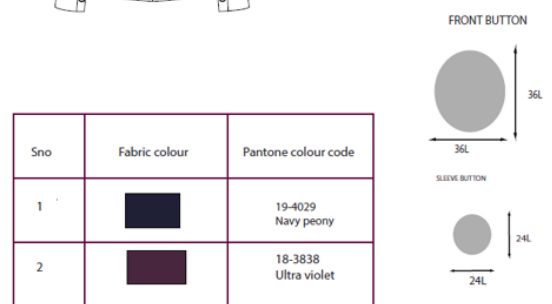

Figure 8: Technical pack of Design-2.

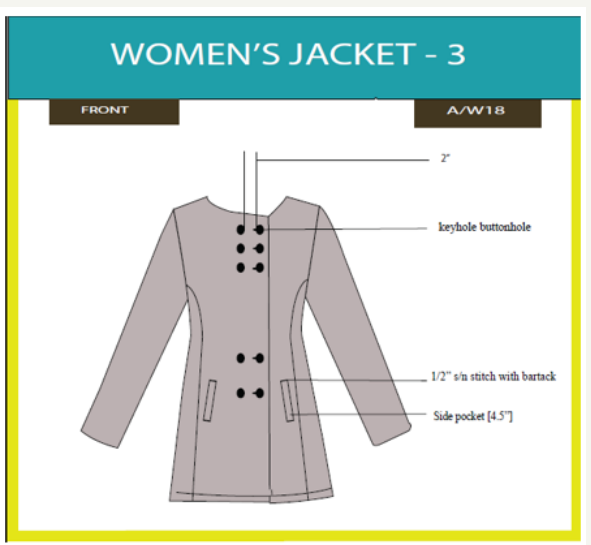

Figure 9

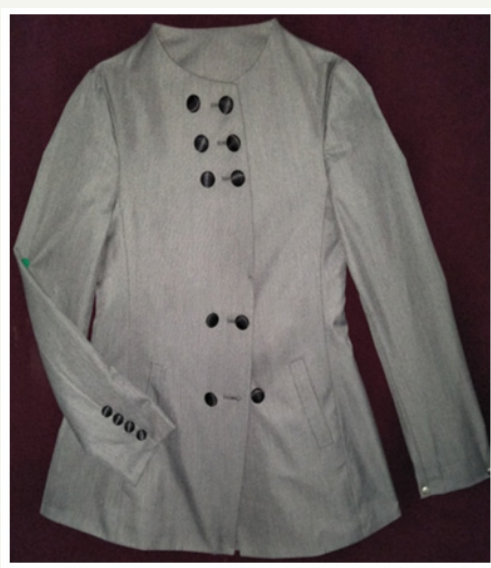

Figure 10: Jacket front. 


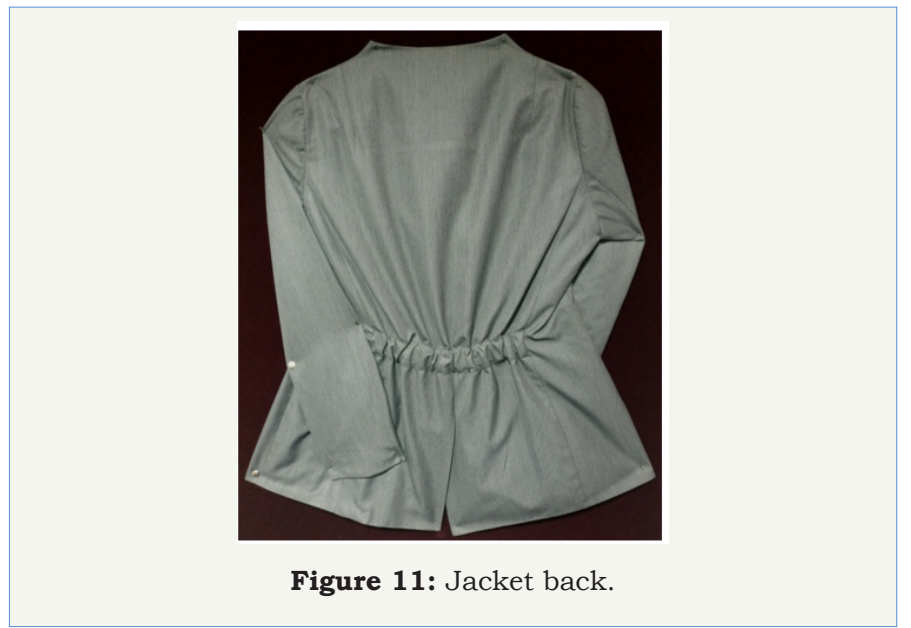

Design 3: This winter jacket has closed high neck with a number of buttons in the front for decorative as well as functional purposes. It has center vent and an elastic band in the back.The unique feature of this jacket is that the elastic in the back provides perfect fit for different sized wearers and detachable hood is provided. This jacket is used as a functional wear, preferably during winter. This jacket avoids carrying additional protective elements while travelling to colder places since it is provided with hood to keep the wearer warm. A provision is made inside the jacket to carry the detached hood. This jacket is designed with a number of pockets inside and out for placing the handy gadgets like mobile phones, iPod, sunglass, headphones, eatables, sanitary napkins. This can be accompanied with jeggings, jeans, leather pants, boots, woolen scarfs, gloves and earmuffs (Figure 12-15).

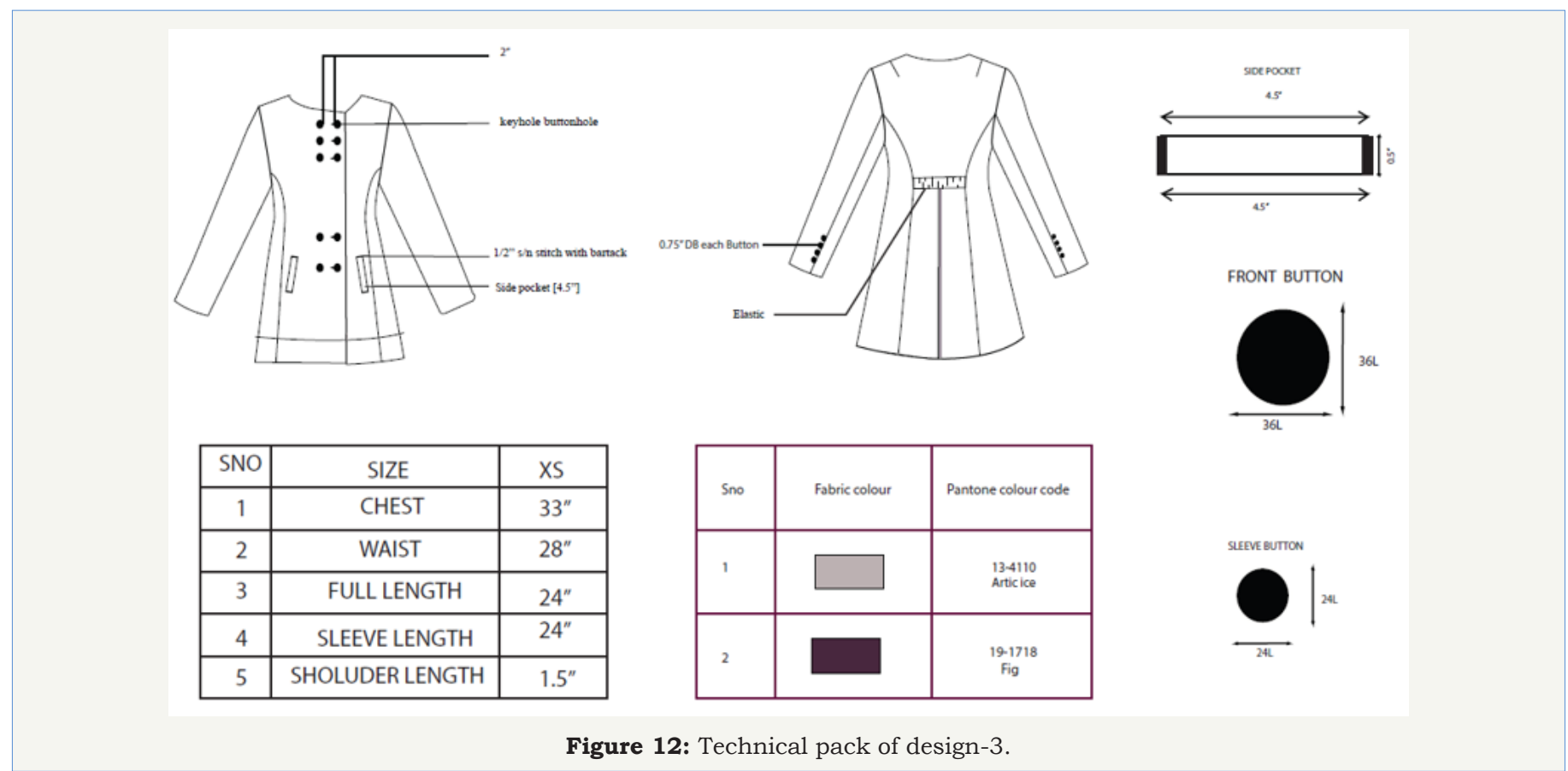

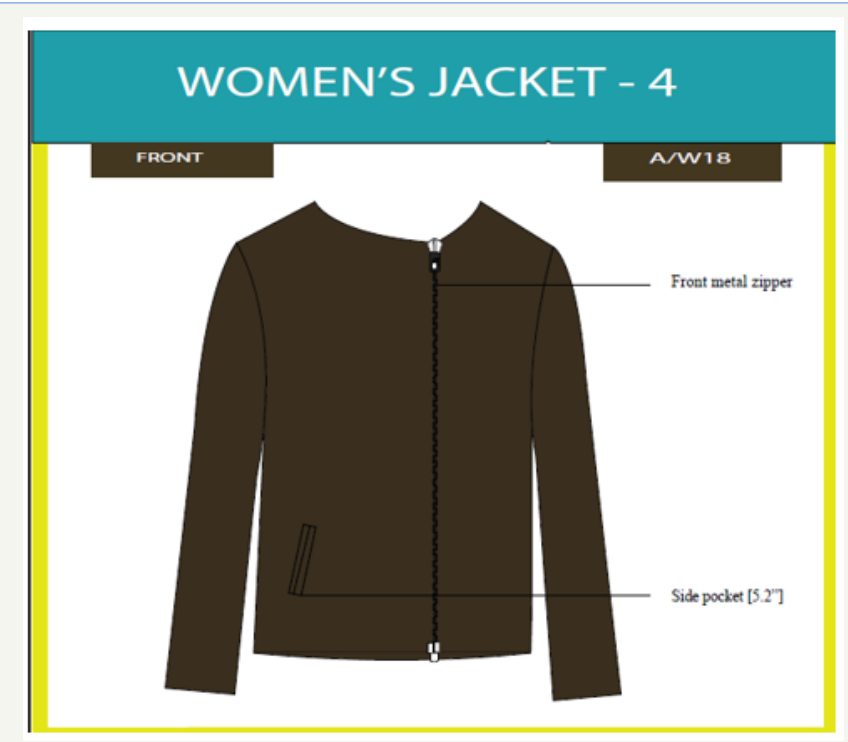

Figure 13

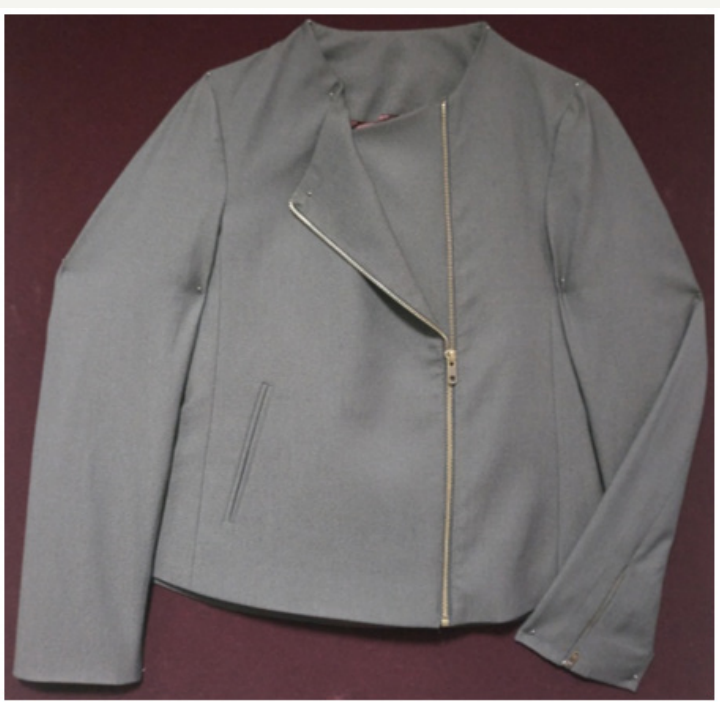

Figure 14: Jacket front. 


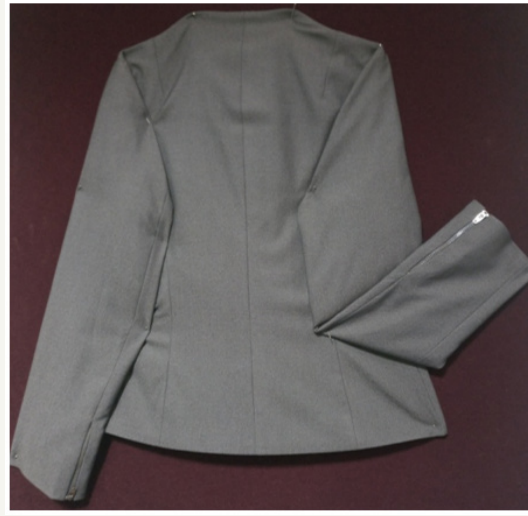

Figure 15: Jacket back.

Design 4: This zipper jacket resembles biker jacket. It has an asymmetrical opening in the front. Metal zipper is used for closure. It has a single diagonal welt pockets in the front and inner provisions for carrying handy gadgets. The sleeves also have a zipper for fastening. It is a multi purpose jacket. It has a provision in the back for carrying laptop and hence it avoids carrying a luggage bag. It is designed in such a way that the feeding mothers feel it comfortable to milk feed their children. It has a thumb hole in the sleeve which can be used like gloves to give proper grip while driving. This jacket is designed for those who cannot afford a leather biker jacket. Thick fabrics and dark shades are chosen for this style as the customers desired. This can be paired with jeans, jeggings, capris, etc (Figure 16-19).
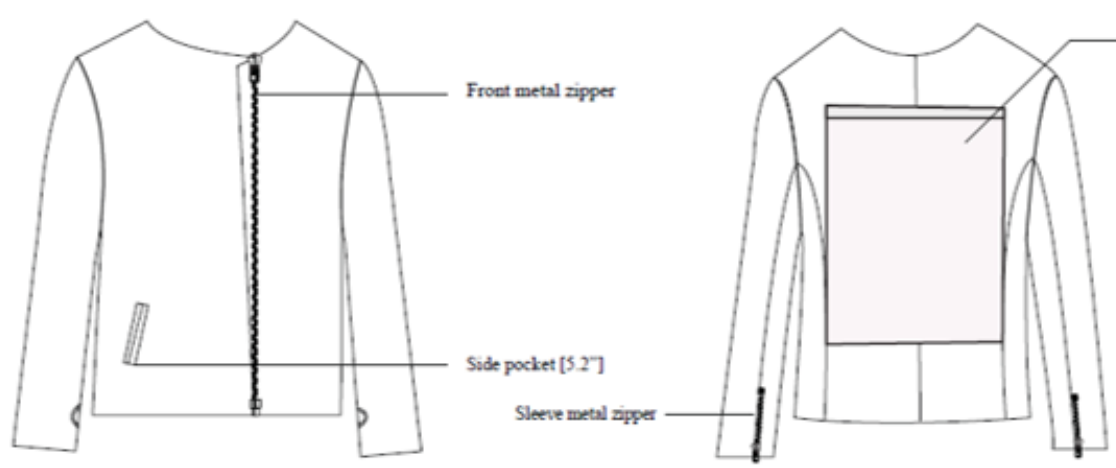

LAPTOP PROVISION

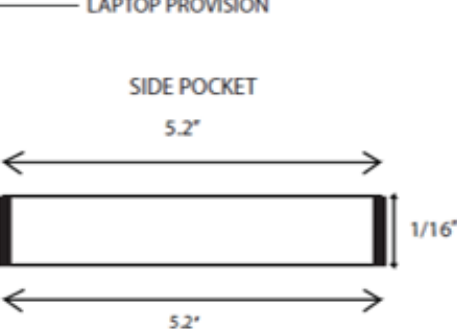

FRONT METAL ZIPPER

$19^{\circ}$

E

\begin{tabular}{|c|c|c|}
\hline SNO & SIZE & S \\
\hline 1 & CHEST & $36^{\prime \prime}$ \\
\hline 2 & WAIST & $30^{\prime \prime}$ \\
\hline 3 & FULL LENGTH & $21^{\prime \prime}$ \\
\hline 4 & SLEEVE LENGTH & $23.5^{\prime \prime}$ \\
\hline 5 & SHOLUDER LENGTH & $15^{\prime \prime}$ \\
\hline
\end{tabular}

\begin{tabular}{|c|c|c|}
\hline Sno & Fabric colour & Pantone colour code \\
\hline 1 & & $\begin{array}{l}18-1112 \\
\text { Walnut }\end{array}$ \\
\hline 2 & & $\begin{array}{l}18-1619 \\
\text { Maroon }\end{array}$ \\
\hline
\end{tabular}

SLEEVE METAL ZIPPER

$45^{\circ}$

Figure 16: Technical pack of design- 4.

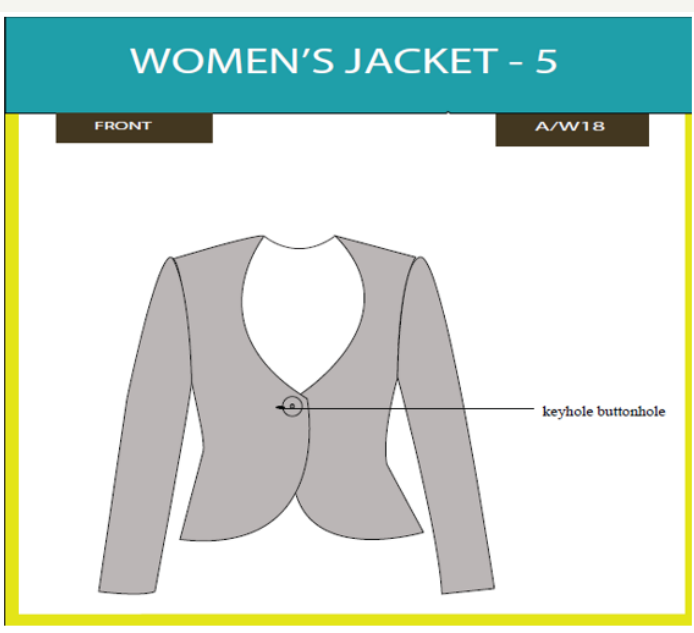

Figure 17

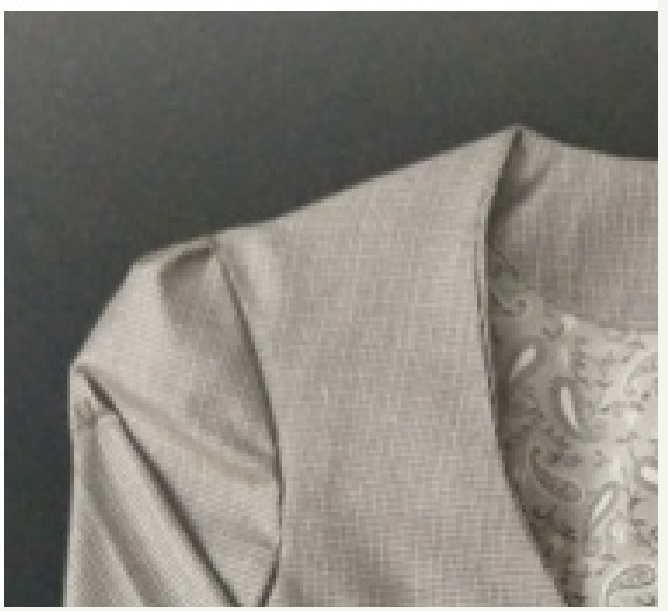

Figure 18: Jacket front. 


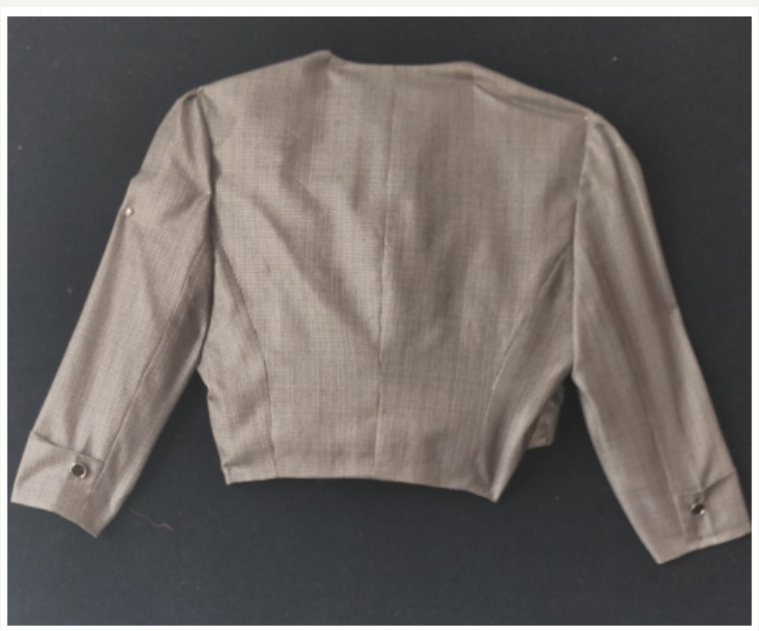

Figure 19: Jacket back.

Design 5: This crop jacket has three-fourth puff sleeve with folded cuff. It has wider front open with slightly overlapping. A single button is used for closure. To implement the retro fashion in the current trend, this party wear is designed with puff sleeve in black and white color combination. This can be accompanied with skirt, leggings, jeggings, palazzo pants, straight pants, culottes. It can also be worn along with dresses. This jacket suits all types of wearers despite their physique (Figure 20).
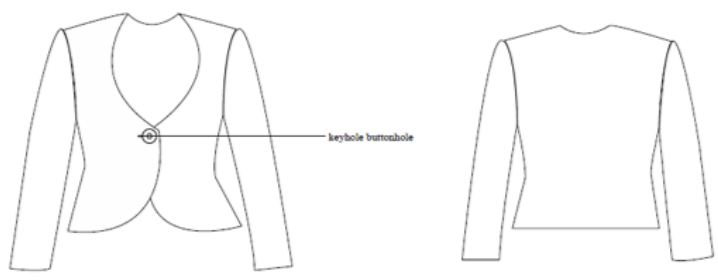

FRONT BUTTON

\begin{tabular}{|c|c|c|}
\hline SNO & SIZE & M \\
\hline 1 & CHEST & $38^{\prime \prime}$ \\
\hline 2 & WAIST & $32^{\prime \prime}$ \\
\hline 3 & FULL LENGTH & $16^{\prime \prime}$ \\
\hline 4 & SLEEVE LENGTH & $24.5^{\prime \prime}$ \\
\hline 5 & SHOLUDER LENGTH & $15.5^{\prime \prime}$ \\
\hline
\end{tabular}

\begin{tabular}{|l|l|c|}
\hline Sno & Fabric colour & Pantone colour code \\
\hline 1 & $\square$ & $\begin{array}{c}15-4702 \\
\text { Puritan grey }\end{array}$ \\
\hline 2 & & $\begin{array}{c}18-3518 \mathrm{TPX} \\
\text { Patrician purple }\end{array}$ \\
\hline
\end{tabular}

Figure 20: Technical pack of design- 5 .

Fabric quality assessment: We have designed five different jackets with the help of SAAI Apparels- UNIT 2, Bangalore. The 4 point system is used for inspecting the fabric roll. The Fabric roll is initially inspected using the 4 point system. Fabric rolls containing more than 40 defective points are rejected
a) $<3-1$ point,
b) 3-6 - 2 points
c) 6-9-3 points
d) $<9-4$ points

Post designing works: The production process involved are spreading, cutting, numbering, fusing, bundling, sewing, pressing and finishing. The fabrics are laid and cut using straight knife and band knife. The cut jacket components are numbered accordingly and are bundled.

\section{Flow process of cad:}

Pattern master develops base pattern

Using digitizer, the hard copy is converted into soft copy

According to spec sheet pattern is graded.

Pattern is developed using DGS system

The pattern is converted to GMS for Marker planning efficiency

According to size ratio, Marker is developed

Plotter prints the marker

The marker is sent to the cutting department for spreading 
These bundles are sent to the sewing department where each operation is carried out by various operators in different sections like lining section, body section and sleeve section. Further the jacket is sent to finishing department for pressing and then packing. AQL of $1.5 \%$ is followed for the finished garments. The different stages of inspection are in-process inspection and whole garment inspection. During inspection, critical defective garments are rejected, whereas minor defective garments are sent for correction.

Final product assessment: The various inspections are done in between each stage or before proceeding to the next process. Inspection is done to ensure the product quality and to avoid defective pieces and thus to reduce the rejection pieces.

The jackets developed were taken to the end-users for obtaining their feedback. These feedbacks were acquired to determine the design, quality, comfort, fit and the cost of the jackets with that of the customer's expectations. The feedback was gained both through personal interaction and online. The feedback questionnaires consisting of 10 questions were developed by us. The quality, comfort, fit and design of the jackets were judged by personally wearing them. The information collected from feedbacks were helpful in understanding customers requirements and expectations. These feedback forms were filled by 300 members.

\section{Customer feedback}

(Table 1)

Table 1: Feedback form.

\begin{tabular}{|c|c|c|c|c|c|c|}
\hline \multirow[t]{2}{*}{ S.no } & \multirow[t]{2}{*}{ Questions } & \multicolumn{5}{|c|}{ Ratings } \\
\hline & & 5 & 4 & 3 & 2 & 1 \\
\hline 1 & How do you feel about the design of the blazer? & & & & & \\
\hline 2 & What rating will give you for the quality of the product? & & & & & \\
\hline 3 & Is the selected colour is suitable and attractive for the final garment? & & & & & \\
\hline 4 & Do you like the trim selection? & & & & & \\
\hline 5 & Does the blazer fit you perfectly? & & & & & \\
\hline 6 & How well does our product fulfil your & & & & & \\
\hline 7 & How much rating will you give for the comfort of the garment while wearing? & & & & & \\
\hline 8 & Does the product is in line with the current trend? & & & & & \\
\hline 9 & Does the design, cut and style created is apt for casual wear? & & & & & \\
\hline 10 & Is the cost for this blazer is reasonable? & & & & & \\
\hline
\end{tabular}

This feedback form is to understand the customer way of choosing the product in the market

(Rating weightings: 5-Excellent, 4-Very good, 3-Good, 2-Average, 1-Poor)

The details obtained are consolidated using bar charts (Figure 21).

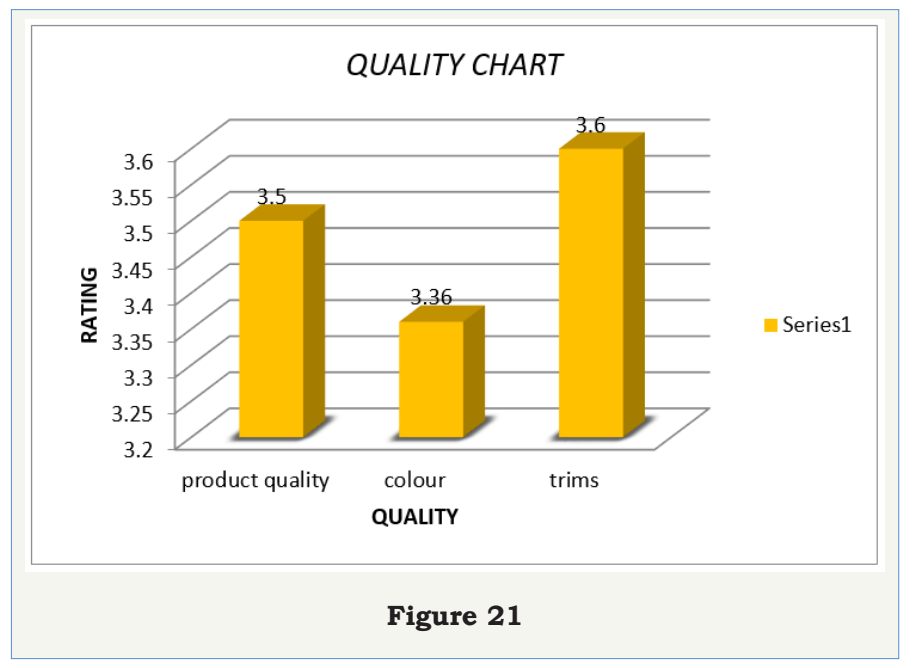

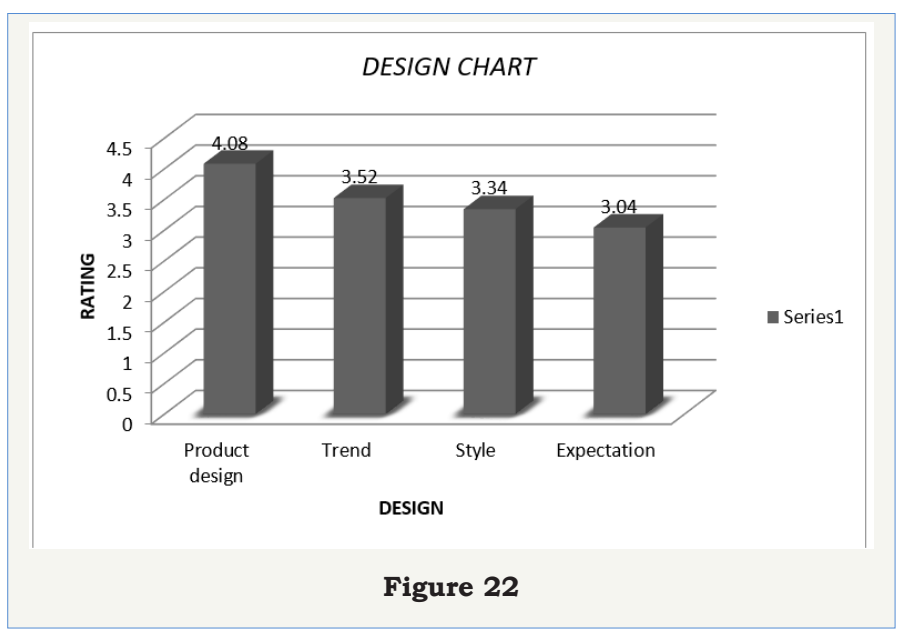

From the quality chart, it is concluded that the trims, quality were very good compared to the product quality and the color selection. Also, customers expect different colors with bright shades 
so that they will be provided with more choices. Since the colour choice differs from person to person based on their taste, achieving a rating of 3.36 is considered to be a fair result (Figure 22).

From the design chart, it is concluded that the customer expectations about the product design, trims selection, and style were fulfilled. And the customers seem to be highly attracted towards the product design. Since the current trend and expectation of 3/4th of the customers are fulfilled, these designs and idea of women jacket can be launched in upcoming seasons for bulk production (Figure 23).

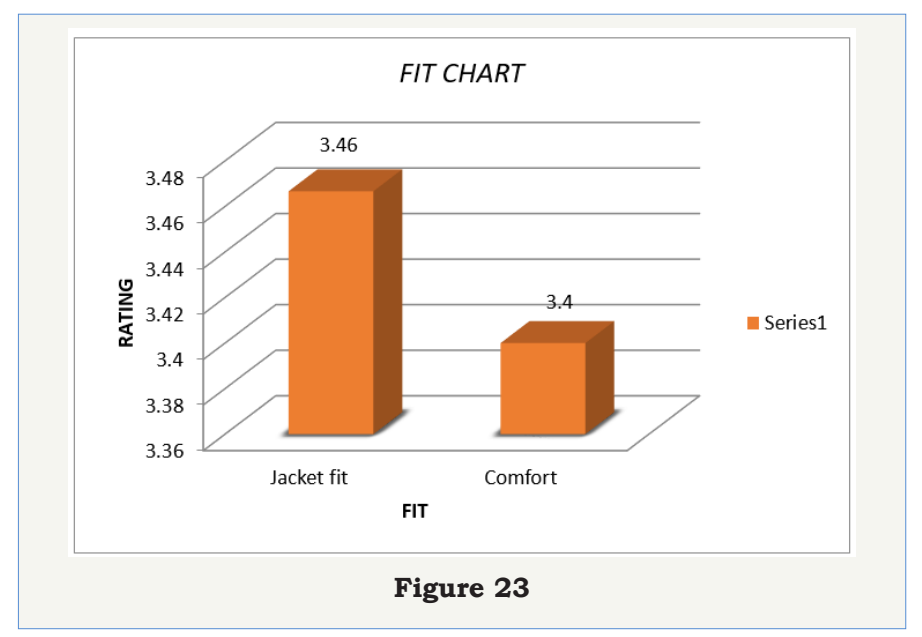

From the Fit chart, it is concluded that the fit is good, but they consider the comfort to be average as it cannot be used for regular use and also due to our climatic condition. The comfort level differs according to the customers' perspective and hence the rating 3.4 is considered as a positive outcome for the jacket (Figure 24).

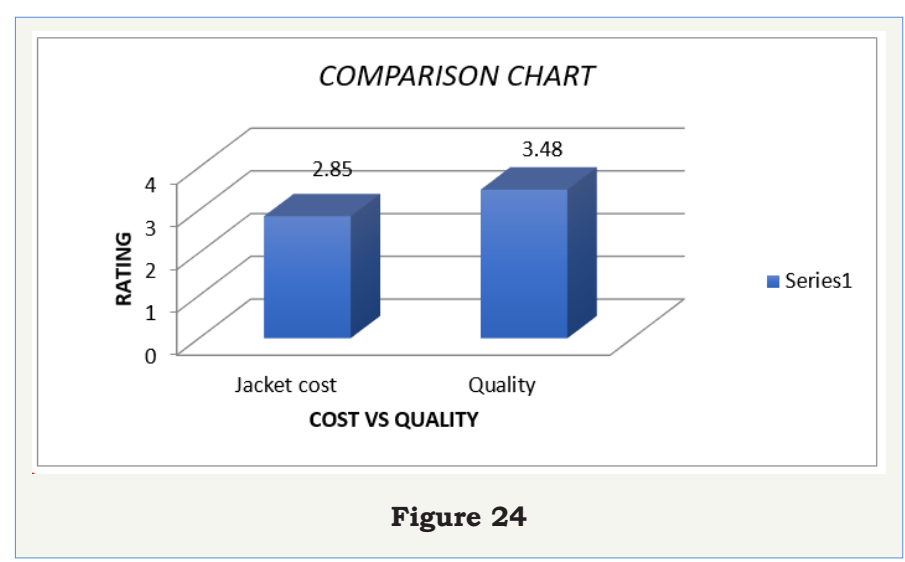

From the cost vs quality chart, the cost of the provided product quality is considered to be high. So it is concluded that the cost of the product is affordable for the working women in metropolitan city compared to others. The fabric quality is apt for the given cost of the product therefore the rating 3.48 is rated through the feedback.

\section{Result}

Thus, in this case study five different women's jackets were designed, produced and the customer feedbacks were received to improve design features. The ratings obtained from the customer feedback are represented in the bar chart as shown above for better understanding of the readers. Thus the jackets developed to satisfy the customer mostly on the basis of their climatic condition, style, comfort and design. Mostly the working women in metropolitan cities are affordable with the cost compared to common people. The compiled result of the feedback from the customers shows that the least rating given by the customer is good and hence further implementation of the product will lead to success in the future.

\section{Conclusion}

The above discussion gives a detailed view on the product development, right from designing to end of production of women jacket to be specific. This begins by identifying the opportunities available in the market. Next, is screening ideas, evaluating the available pool of ideas, and then developing the product. This helps us in understanding the workflow in obtaining a finished product. Product development is very important as it ensures quality, with suitable fit, fashionable and attractive appearance and speeds up to meet with consumer satisfaction. Current trends along with people's comfort while wearing the jacket should be taken as the primary objective. Designing is the initial stage for the development of a product. Hence it requires too much attention and smart work. However, when designing the product, one must keep in the mind the unique features of the product development and must meet the needs of the customers. This article explains each and every process of designing and developing the product. It will guide the upcoming designers to produce a successful product.

\section{Limitations and Scope for Future Study}

a) The jackets are suitably designed for an age group and this can be preceded further by designing jackets for various age groups.

b) Only limited styles of $\mathrm{w}$

\section{References}

1. Wheelwright SC, Clark KB (1992) Revolutionizing product development: quantum leaps in speed, efficiency, and quality. Simon and Schuster, USA.

2. Veryzer RW, Borja de Mozota B (2005) The impact of user-oriented design on new product development: An examination of fundamental relationships. Journal of product innovation management 22(2): 128143.

3. O'Cass A (2000) An assessment of consumers product, purchase decision, advertising and consumption involvement in fashion clothing. Journal of Economic Psychology 21(5): 545-576.

4. Hines T, Bruce M (2007) Fashion marketing. Routledge, UK.

5. Giovannini S, Xu Y, Thomas J (2015) Luxury fashion consumption and Generation Y consumers: Self, brand consciousness, and consumption motivations. Journal of fashion marketing and management 19(1): 2240.

6. Lu J, Ma J, Zhang G, Zhu Y, Zeng X, Koehl L (2011) Theme-based comprehensive evaluation in new product development using fuzzy hierarchical criteria group decision-making method. IEEE Transactions on Industrial Electronics 58(6): 2236-2246.

7. Khare A, Mishra A, Parveen C (2012) Influence of collective self esteem on fashion clothing involvement among Indian women. Journal of 
Fashion Marketing and Management: An International Journal 16(1): 42-63.

8. O'Cass A (2004) Fashion clothing consumption: antecedents and consequences of fashion clothing involvement. European Journal of Marketing 38(7): 869-882.

9. Bhardwaj V, Fairhurst A (2010) Fast fashion: response to changes in the fashion industry. The International Review of Retail, Distribution and Consumer Research 20(1): 165-173.

10. Hourigan SR, Bougoure US (2012) Towards a better understanding of fashion clothing involvement. Australasian Marketing Journal (AMJ) 20(2): 127-135.
11. Goldsmith R, Moore MA, Beaudoin P (1999) Fashion innovativeness and self-concept: a replication. Journal of Product \& Brand Management 8(1): 7-18.

12. O'Cass A, Julian CC (2001) Fashion clothing consumption: studying the effects of materialistic values, self-image/product-image congruency relationships, gender and age on fashion clothing involvement. Southern Cross University, pp. 1-9. (c) (i) Creative Commons Attribution 4.0 International License

For possible submissions Click Here Submit Article

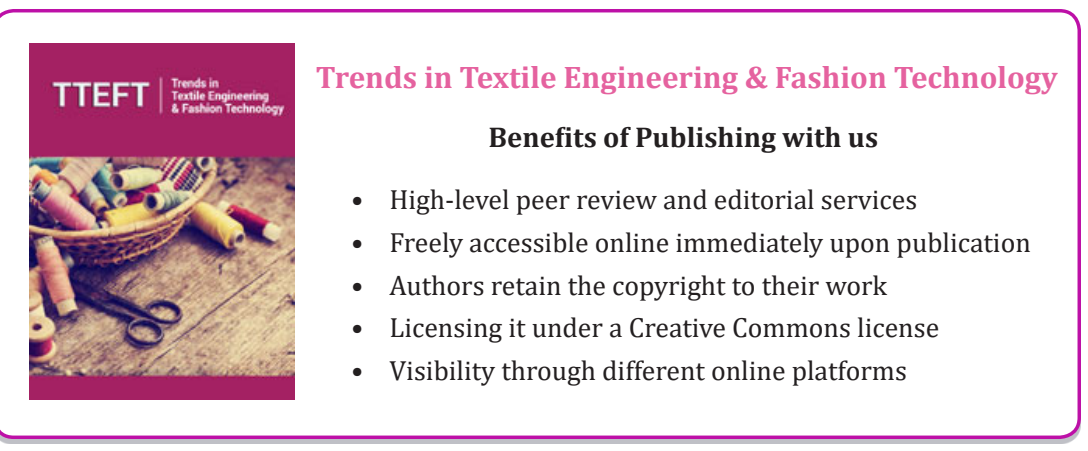

